\title{
BRCA1 negatively regulates IGF-1 expression through an estrogen-responsive element-like site
}

\author{
HJ Kang ${ }^{1,4}$, YW Yi ${ }^{1,2,4}$, HJ Kim ${ }^{1}$, YB Hong ${ }^{1,2}$, YS Seong ${ }^{2}$ and I Bae ${ }^{\star, 1,2,3}$
}

The insulin-like growth factor-1 receptor (IGF-1R) signaling pathway is critical for both normal mammary gland development and malignant transformation. It has been reported that the IGF-1 stimulates breast cancer cell proliferation and is upregulated in tumors with BRCA1/2 mutations. We report here that IGF-1 is negatively regulated by BRCA1 at the transcriptional level in human breast cancer cells. BRCA1 knockdown (BRCA1-KD) induces the expression of IGF-1 mRNA in MCF7 cells in an estrogen receptor $\alpha(E R \alpha)$-dependent manner. We found that both BRCA1 and ER $\alpha$ bind to the endogenous IGF-1 promoter region containing an estrogen-responsive element-like (EREL) site. BRCA1-KD does not significantly affect ER $\alpha$ binding on the IGF-1 promoter. Reporter analysis demonstrates that BRCA1 could regulate IGF-1 transcripts via this EREL site. In addition, enzymelinked immunosorbent assay revealed that de-repression of IGF-1 transcription by BRCA1-KD increases the level of extracellular IGF-1 protein, and secreted IGF-1 seems to increase the phospho-IGF-1R $\beta$ and activate its downstream signaling pathway. Blocking the IGF-1/IGF-1R/phosphoinositide 3-kinase (PI3K)/AKT pathway either by a neutralizing antibody or by small-molecule inhibitors preferentially reduces the proliferation of BRCA1-KD cells. Furthermore, the IGF-1-EREL-LuC reporter assay demonstrates that various inhibitors, which can inhibit the IGF-1R pathway, can suppress this reporter activity. These findings suggest that BRCA1 defectiveness keeps turning on IGF-1/PI3K/AKT signaling, which significantly contributes to increase cell survival and proliferation.

Cell Death and Disease (2012) 3, e336; doi:10.1038/cddis.2012.78; published online 28 June 2012

Subject Category: Cancer

The insulin-like growth factors (IGFs), both IGF-1 and IGF-2, are peptide hormones that have important roles in mammalian growth and development. ${ }^{1}$ IGF-1 is structurally similar to insulin, but has a much higher growth-promoting activity (http://www.uniprot.org/). IGF-1 binds to the IGF-1 receptor (IGF-1R) homodimer or the IGF-1R/insulin receptor heterodimer and provokes intracellular signaling cascades., ${ }^{2,3}$ Similar to insulin, IGF-1 not only acts as a growth factor at the cellular level but also functions as a hormone regulating growth and energy metabolism at the whole-organism level. ${ }^{3}$

IGF-1R is activated by extracellular IGF-1 and is autophosphorylated at multiple tyrosine residues in its kinase domain. ${ }^{4}$ Activation of IGF-1R induces the diverse signaling pathways such as the phosphoinositide 3-kinase (PI3K)/AKT and the mitogen-activated protein kinase (MAPK) pathways that are important to cell proliferation, transformation and survival. ${ }^{3-5}$ IGF-1R is commonly expressed in human cancers including breast cancers. ${ }^{3-5}$ Phospho-IGF-1R is detected by immunostaining in about half of breast tumors irrespective of their subtypes, which is associated with poor outcome. ${ }^{5}$

The transcriptional regulation of human IGF-1 is not well understood yet. Although mouse Igf- 1 is regulated by estrogen via direct binding of estrogen receptor $\alpha(E R \alpha)$ to estrogen-responsive elements (EREs) in its promoter, ${ }^{6}$ there is no known consensus ERE in the human IGF-1 promoter. ${ }^{7,8}$ The chromatin immunoprecipitation (ChIP) analysis, however, demonstrates that $\mathrm{ER} \alpha$ binds to human IGF-1 promoter region, ${ }^{8}$ and human IGF-1 mRNA expression is activated by estrogen in human ovarian and breast cancer cell lines. ${ }^{7,8}$ Furthermore, intratumoral IGF-1 protein is elevated in breast cancer patients carrying breast cancer susceptibility gene 1/2 (BRCA1/2) mutations. ${ }^{9}$ Although it has been shown that siRNA-based BRCA1 knockdown (BRCA1-KD) induces intracellular IGF-1 levels in primary human mammary gland cells, ${ }^{9}$ the underlying molecular mechanism in human normal or tumor cells still remains to be determined.

\footnotetext{
${ }^{1}$ Department of Oncology, Lombardi Comprehensive Cancer Center, Georgetown University, Washington, DC, USA; ${ }^{2}$ Department of Nanobiomedical Science and WCU (World Class University) Research Center of Nanobiomedical Science, Dankook University, Cheonan, Korea and ${ }^{3}$ Department of Radiation Medicine, Lombardi Comprehensive Cancer Center, Georgetown University, Washington, DC, USA

${ }^{*}$ Corresponding author: I Bae, Department of Oncology, Lombardi Comprehensive Cancer Center, Georgetown University, Washington, DC 20057, USA. Tel: 202 687 5267; Fax: 202687 2847; E-mail: ib42@georgetown.edu

${ }^{4}$ These authors contributed equally to this work.

Keywords: BRCA1; IGF-1; negative regulation; ER $\alpha$; positive-feedback activation

Abbreviations: AP1, activator protein 1; BRCA1/2, breast cancer susceptibility gene 1/2; BRCA1-KD, BRCA1 knockdown; ChIP, chromatin immunoprecipitation; CS-FBS, charcoal-stripped fetal bovine serum; DMEM, Dulbecco's Modified Eagle Medium; DMSO, dimethyl sulfoxide; E2, estradiol; ELISA, enzyme-linked immunosorbent assay; ERE, estrogen-responsive element; EREL, estrogen-responsive element-like; ER $\alpha$, estrogen receptor $\alpha$; GSK3 $\beta$, glycogen synthase kinase 3 beta; HI-FBS, heat-inactivated fetal bovine serum; IGF-1/2, insulin-like growth factor-1/2; IGF-1R, insulin-like growth factor-1 receptor; Luc, luciferase; MAPK, mitogen-activated protein kinase; MTT, 3-(4,5-dimethylthiazol-2-yl)-2,5-diphenyltetrazolium bromide; PI3K, phosphoinositide 3-kinase; qRT-PCR, quantitative real-time PCR; STAT1, signal transducers and activators of transcription 1; ZBRK1, zinc finger and BRCA1-interacting protein with a KRAB domain 1

Received 26.4.12; revised 15.5.12; accepted 17.5.12; Edited by G Raschellá
} 
Germline mutations in the BRCA1 gene drastically increase the risk of breast and ovarian cancers in the individuals who carry them. ${ }^{10,11}$ In addition, the level of BRCA1 protein is also often decreased or absent in sporadic breast and ovarian cancers. ${ }^{12,13}$ As a tumor suppressor, BRCA1 is involved in the regulation of cell-cycle progression, DNA damage and repair and maintenance of genomic integrity. ${ }^{14}$ Although BRCA1 is not a sequence-specific DNA-binding protein, it functions as a transcriptional modulators via physical interaction with various transcription factors (such as ER $\alpha$, p53, STAT1, c-Myc, and ZBRK1) and regulates their target gene expression. ${ }^{15} \mathrm{ER} \alpha$, a member of the steroid hormone receptor superfamily, is activated by estrogen and has important roles in normal development and tumorigenesis of the breast. ${ }^{2}$ BRCA1 interacts with $E R \alpha$ and represses the $E R \alpha$-mediated transcriptional activity either in an estradiol (E2)-dependent ${ }^{16}$ or -independent manner. ${ }^{17}$

In this paper, we report that BRCA1 represses IGF-1 transcription in an ER $\alpha$-dependent manner. Our study also suggests that de-repression of IGF-1 transcription by BRCA1 knockdown may induce a positive-feedback loop in an autocrine manner and result in further activation of IGF-1 transcripts through the IGF-1R/PI3K/AKT pathway.

\section{Results}

Expression of IGF-1 is negatively regulated by BRCA1. In order to identify genes regulated by BRCA1, we performed microarray analysis using RNA samples from MCF7 cells transfected with siRNA (control versus BRCA1). One of the genes that were significantly upregulated by BRCA1-KD was IGF-1 (data not shown). To further confirm this, we performed quantitative real-time PCR (qRT-PCR) analysis and found that BRCA1-KD significantly increased the level of IGF-1 mRNA in the human breast cancer cell line, MCF7 and prostate cancer cell line, DU145 - both of which are ER $\alpha$-positive (Figures $1 a$ and $b$ ). However, BRCA1-KD did not significantly change the expression of IGF-2, IGF-1R, and IRS-1 in MCF7 cells (Supplementary Figure S1). Interestingly, BRCA1-KD did not affect IGF-1 gene expression in two ER-negative breast cancer cell lines, MCF10A and MDA-MB-231 (data not shown), suggesting the potential involvement of $\mathrm{ER} \alpha$ in the regulation of IGF-1 by BRCA1. In addition, overexpression of wild-type BRCA1 significantly decreased the level of IGF-1 mRNA in MCF7 cells (Figure 1c).

To further evaluate estradiol (E2) dependency, we performed qRT-PCR analysis with MCF7 cells treated with SiRNA (control versus BRCA1) under either normal growth or E2-stimulated conditions in the absence or presence of an antiestrogen, ICl182780. Under normal growth conditions, BRCA1-KD-induced IGF-1 mRNA expression was significantly but not completely reduced by ICI182780 (Figure 1d), whereas treatment of ICl182780 nearly completely abolished BRCA1-KD-induced IGF-1 mRNA expression in E2-stimulated MCF7 cells (Figure 1e). These results suggest that the induction of IGF-1 mRNA expression is estrogen-dependent in BRCA1-KD MCF7 cells under E2-stimulated conditions. ICl182780 also reduced IGF-1 mRNA expression levels of control-siRNA-treated MCF7 cells in both normal growth and E2-stimulated conditions. Under these conditions, administration of $\mathrm{ICl} 182780$ reduced the BRCA1 mRNA expression level in control-siRNA-treated MCF7 cells in both conditions (Figures 1d and e). It has been reported that ICl182780 inhibited E2-induced BRCA1 mRNA induction in ER-positive cells. ${ }^{18}$

BRCA1 represses the human IGF-1 promoter through an ERE-like site. Although it is reported that human IGF-1 gene expression is regulated by estrogen in human ovarian and breast cancer cell lines, no known consensus ERE site has been reported in human IGF-1 promoter. ${ }^{7,8}$ Interestingly, the chicken promoter contains an ERE-like (EREL) site, but a reporter construct containing mutations of this EREL site is still activated by estrogen in human hepatocellular carcinoma HepG2 cells. ${ }^{19}$ Sasaki et al., ${ }^{8}$ however, subsequently demonstrated by ChIP analysis that ER $\alpha$ binds to the human IGF-1 promoter region $(-111$ to -312$)$ containing this EREL site in human ovarian cancer cell lines and described that this region contains an activator protein 1 (AP1) site.

To identify potential sequence elements that involve E2-dependent regulation of the human IGF-1 promoter, we performed sequence analysis of this IGF-1 promoter region. Sequence analysis of this region failed to identify consensus ERE (GGTCAnnnTGACC) or AP1 ( $\left.{ }^{\top} /{ }_{G} A G T C A G\right)$ site. Instead, an EREL site, as previously identified in the chicken IGF-1 promoter, ${ }^{19}$ is highly conserved in human, mouse, and chicken IGF-1 promoters (Figure 2a).

To determine whether BRCA1 and/or ER $\alpha$ binds to this region, we further performed ChIP analysis under E2-stimulated conditions. The ChIP assay revealed the occupation of both $\mathrm{ER} \alpha$ and BRCA1 on the IGF-1 promoter region containing this EREL site in MCF7 cells (Figures $2 b$ and $c$ ). BRCA1-KD abolished the interaction of BRCA1 with the human IGF-1 promoter in an E2-independent manner (Figures $2 \mathrm{~b}$ and $\mathrm{c}$ ). BRCA1-KD itself did not significantly affect $E R \alpha$ binding to the human IGF-1 promoter in MCF7 cells under estrogen-deprived conditions (Figure 2c, lower). On the contrary, stimulation by E2 markedly increased $\mathrm{ER} \alpha$ binding on the IGF-1 promoter in both control and BRCA1-KD MCF7 cells (Figures $2 b$ and $c$ ). As expected, the antiestrogen, $\mathrm{ICl} 182780$, reduced E2-induced $\mathrm{ER} \alpha$ binding to the IGF-1 promoter.

Next, we prepared three different reporter constructs of the human IGF-1 promoter: (1) IGF-1-1 kb-Luc, (2) IGF-1EREL-Luc construct contained one copy of wild-type EREL sequence, and (3) IGF-1-EREL-Luc construct contained the mutant EREL sequence. In estrogen-deprived MCF7 cells, E2 administration induced reporter activities from both IGF-1-1kb-Luc (Supplementary Figure S2a) and wildtype IGF-1-EREL-Luc (Figure 3a) in a dose-dependent manner. Mutation of the EREL site completely abolished E2-induced expression of the reporter gene (Figure 3a). Under these conditions, we found that $10 \mathrm{nM}$ of E2 induced approximately five-fold increase in the reporter activity from a control reporter containing a consensus ERE element (Figure 3b). In addition, transient overexpression of BRCA1 suppressed the E2-induced wild-type IGF-1-ELEL-Luc reporter activity in a dose-independent manner, whereas little or no effect was observed in the absence of E2 (Figure 3c). 

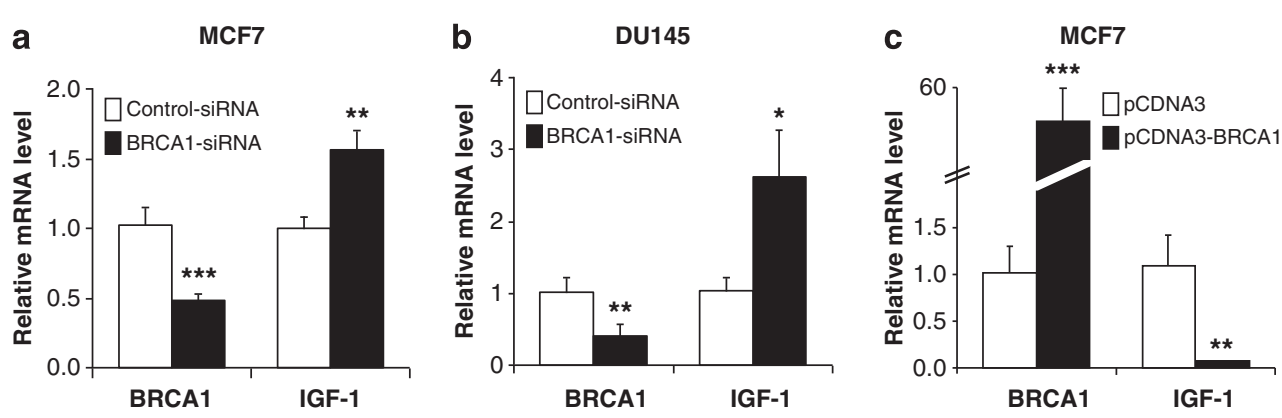

d

IGF-1

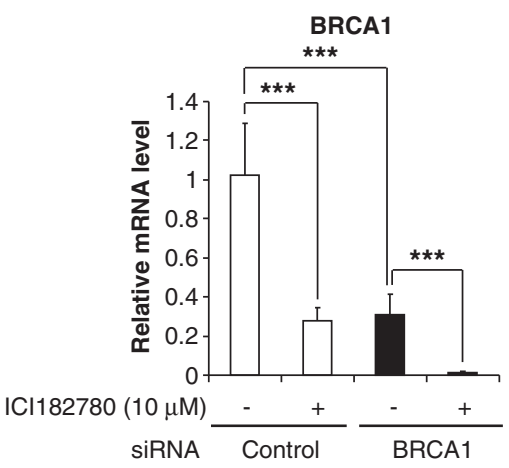

e
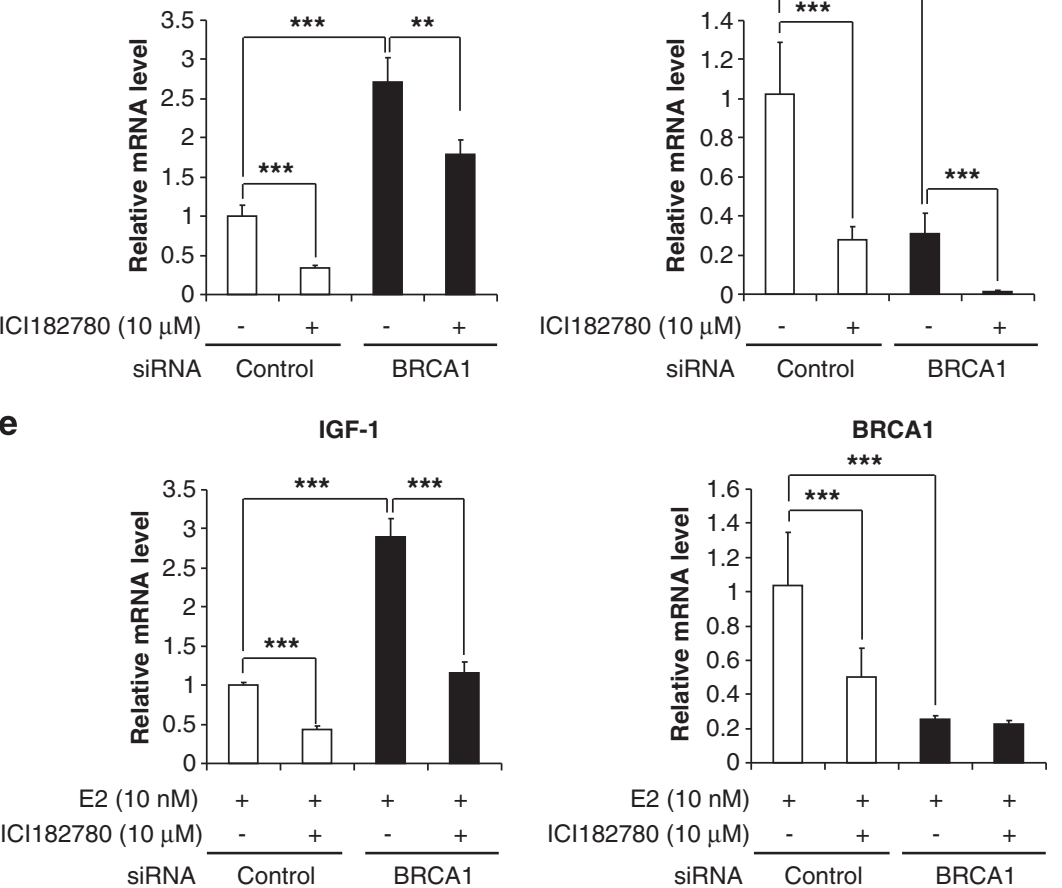

Figure 1 Negative regulation of IGF-1 mRNA expression by BRCA1. (a and $\mathbf{b}$ ) Total RNAs extracted from cells transfected with $100 \mathrm{nM}$ of siRNA (control versus BRCA1) for $72 \mathrm{~h}$ were used for qRT-PCR assay to quantify the level of BRCA1 and IGF-1 transcripts in MCF7 and DU145 cells. (c) Total RNAs isolated from the cells transfected with $1 \mu \mathrm{g}$ of DNA expression vector (control versus BRCA1) for $24 \mathrm{~h}$ were subjected to qRT-PCR assay analysis as in (a and $\mathbf{b}$ ). (d) Total RNAs were extracted from MCF7 cells transfected with $100 \mathrm{nM}$ of siRNA (control versus BRCA1) for $48 \mathrm{~h}$ followed by $24 \mathrm{~h}$ treatment of ICl182780 under normal growth conditions and used for qRT-PCR assay to monitor the levels of BRCA1 and IGF-1 transcripts. (e) MCF7 cells cultured with phenol-red-free DMEM supplemented with charcoal-stripped FBS (CS-FBS) were transfected with $100 \mathrm{nM}$ siRNA (control versus BRCA1) for 3 days. Transfected cells were further treated with $10 \mu \mathrm{M}$ ICl182780 for $24 \mathrm{~h}$ and stimulated by $10 \mathrm{nM}$ of $\mathrm{E} 2$ in phenol-red-free DMEM containing CS-FBS. After extraction of total RNAs, qRT-PCR assays were performed as in (d). Representative data from two independent experiments performed in triplicate are shown as mean \pm S.E.M. ${ }^{*} P<0.05 ;{ }^{* \star} P<0.01$ and ${ }^{\star \star \star} P<0.001$

Consistently, BRCA1-KD increased the reporter activity from wild-type IGF-1-EREL-Luc in MCF7 cells under E2-stimulated conditions (Figure 3d). Interestingly, BRCA1-KD could induce IGF-1-EREL-Luc reporter activity even in the absence of E2 stimulation (Figure 3d), whereas mutation of the EREL site completely abolished BRCA1-KD-dependent induction of reporter activity. BRCA1-KD also induced activation of IGF-1$1 \mathrm{~kb}$-Luc (Supplementary Figure S2b), wild-type IGF-1-ERELLuc, and consensus ERE-Luc (Supplementary Figure S2c) in MCF7 cells under normal growth conditions.

Carboxy-terminal domain of BRCA1 has important roles in the regulation of human IGF-1 promoter. A previous study reports that the amino-terminus of BRCA1 interacts with $\mathrm{ER} \alpha$, whereas the carboxy-terminus of BRCA1 functions as a transcriptional repression domain using consensus ERE-Luc promoter reporter gene. ${ }^{20}$ To determine the effects of BRCA1 tumor-associated mutations on transcriptional regulation by the EREL site of the human IGF-1 promoter, we performed reporter gene assays with wild-type IGF-1EREL-Luc in the presence of various BRCA1 mutants and wild-type BRCA1 (Figure 4). The wild-type BRCA1 suppressed this reporter activity in the presence of E2 $(38.4 \pm 2.0 \%)$, compared with pCDNA3-transfected control $(100 \pm 3.7 \%)$. A tumor-associated BRCA1 mutant, carrying the T300G mutation in the amino-terminal RING domain, suppressed the reporter activity to the similar levels as wildtype BRCA1 (30.7 $\pm 3.1 \%)$. However, one carboxy-terminal 
a
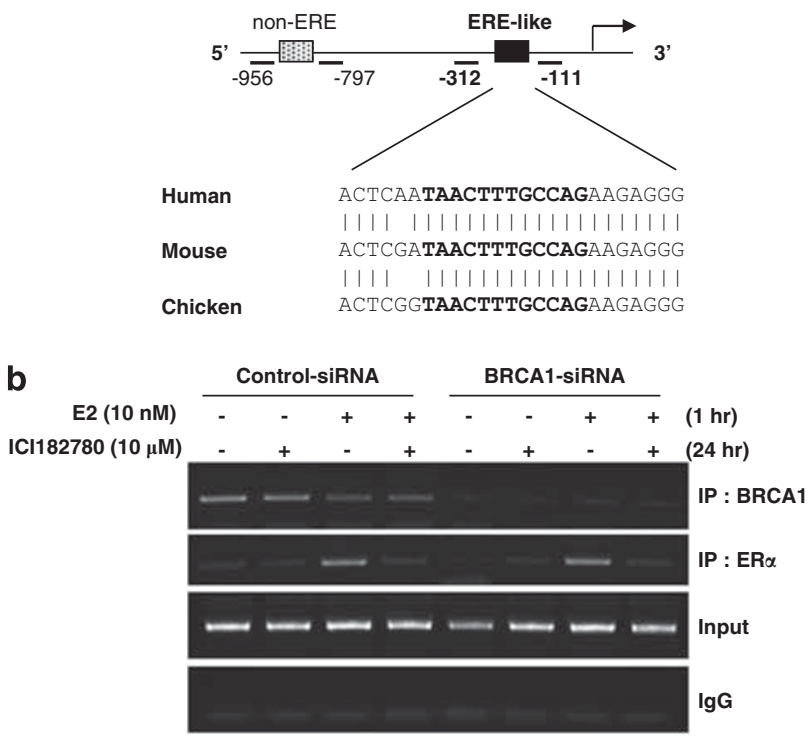

C

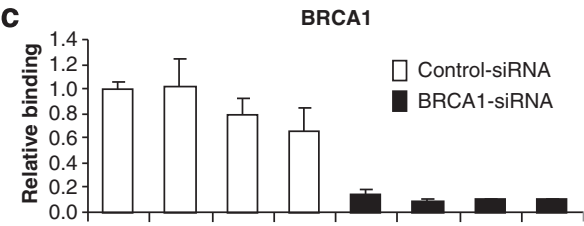

ER $\alpha$

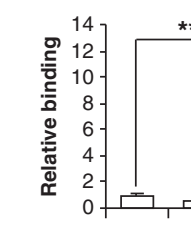

E2 $(10 \mathrm{nM})$

ICl182780 (10 $\mu \mathrm{M})$

Figure 2 Binding of endogenous BRCA1 and $\mathrm{ER} \alpha$ to the promoter regions of human IGF-1. (a) Schematic diagram of the human IGF-1 promoter showing the location and sequence of the ERE-like (EREL) sequence. (b) Cells pretreated with siRNA (control versus BRCA1) were used for ChIP assay. Endogenous promoter regions associated with $B R C A 1$ and/or ER $\alpha$ were immunoprecipitated with antiBRCA1 or anti-ER $\alpha$ antibody, respectively. The relative amounts of IGF-1 promoterspecific DNA containing the EREL site in immunoprecipitated complexes were then determined by semiquantitative PCR as described in Materials and Methods. The non-ERE region in IGF-1 promoter was used as negative control. (c) Using the same DNA samples obtained in (b) qRT-PCR was performed. (b and $\mathbf{c}$ ) Representative data from two independent experiments performed in duplicate are shown as mean \pm S.E.M. ${ }^{* \star *} P<0.001$

tumor mutant, 5382insC (Q1756term), failed to suppress wild-type IGF-1-EREL-Luc reporter activity (82.1 $\pm 7.5 \%$ ). Similarly, another carboxy-terminal BRCA1 mutant, 5677insA (Y1853term), also showed reduced suppression of reporter activity $(74.0 \pm 2.4 \%)$. Because all three BRCA1 mutants are known to physically interact with $\mathrm{ER} \alpha,{ }^{20}$ these results indicate that the carboxyl-terminal domain of BRCA1 is important in repressing IGF-1-EREL-Luc reporter activity. In addition, a carboxy-terminal deletion mutant (BamHI (NT); aa 1-1313) did not repress reporter activity at all $(107.0 \pm 4.9 \%)$. These results suggest that the intact carboxy-terminal repression domain has important functions in suppressing E2-induced IGF-1 reporter activity. Interestingly, the carboxy-terminal domain of BRCA1 (BamHI (CT); aa 1314-1863), which lacks the ER $\alpha$-interacting domain, still has partial repression activity on the wild-type IGF-1-EREL-Luc reporter $(61.9 \pm 3.5 \%)$.

Secreted IGF-1 autocrinely activates the IGF-1R pathway in BRCA1-KD MCF7 cells. To determine the effect of BRCA1-KD on IGF-1 secretion, we measured IGF-1 protein in the culture medium by enzyme-linked immunosorbent assay (ELISA). The culture media harvested from cells treated with siRNA (control versus BRCA1) for $72 \mathrm{~h}$ were subjected to ELISA analysis. The amount of the secreted IGF-1 protein was significantly increased in BRCA1-KD MCF7 cells and administration of an IGF-1 neutralizing antibody completely reduced the secreted IGF-1 protein in these cells (Figure 5a). In addition, BRCA1-KD also induced IGF-1 secretion in another ER $\alpha$-positive cell line, DU145, but not in $\mathrm{ER} \alpha$-negative MCF10A cells (Figure $5 b$ ).

To further evaluate the effect of IGF-1 induction by BRCA1-KD, we performed western blot analysis. BRCA1-KD induced phospho-IGF-1R $\beta$ (Y1135), while there were barely detectable levels of phospho-IGF-1R $\beta$ in control-siRNA-treated cells (Figure 6a). Phosphorylation of AKT, a downstream effector of the IGF-1R pathway, at S473 was also increased by BRCA1-KD. Increase in phospho-IGF-1R $\beta$ was also observed in the BRCA1-KD DU145 cells (Figure 6b), whereas no significant increase of phospho-IGF-1R $\beta$ was observed in BRCA1-KD MCF10A cells (Figure 6b). Consistently, overexpression of wild-type BRCA1 in MCF7 cells further decreased basal levels of phospho-IGF-1R $\beta$ (Supplementary Figure S3a).

The specificity of increased IGF-1R $\beta$ phosphorylation was further confirmed by either a neutralizing antibody or a smallmolecule inhibitor. Administration of a neutralizing IGF-1 antibody abolished BRCA1-KD-induced phospho-IGF-1R $\beta$ (Y1135) and phospho-AKT (S473) in a dose-dependent manner (Figure 6a). In addition, an IGF-1R tyrosine kinase inhibitor, BMS-536924, (Supplementary Table S1) also inhibited phospho-IGF-1R $\beta$ (Y1135), phospho-ATK (S473), and phospho-GSK3 $\beta$ (S9) in a dose-dependent manner in BRCA1-KD MCF7 cells (Figure 6c). Treatment of BMS536924 reduced levels of BRCA1 in control-siRNA-transfected MCF7 cells in a dose-dependent manner (Figure 6c). Moreover, treatment with ICl182780 blocked BRCA1-KDinduced phosphorylation of IGF-1R $\beta$ (Y1135) and AKT (S473) in MCF7 cells cultured in either normal growth conditions (Supplementary Figure S3b) or E2-stimulated conditions (Supplementary Figure $3 c$ ). All these results support that the loss of BRCA1 function can autocrinely activate the IGF-1R pathway in an E2-dependent manner.

Knockdown of BRCA1 sensitizes MCF7 and ZR-75-1 cells to IGF-1R inhibitors. Next, we performed 3-(4,5-dimethylthiazol-2-yl)-2,5-diphenyltetrazolium bromide (MTT) assays to determine the cytotoxic effects of small-molecule IGF-1R inhibitors, BMS-536924 and GSK1904529A, in BRCA1-KD ER $\alpha$-positive breast cancer cell lines. MCF7 cells pretreated with siRNA (control versus BRCA1) were incubated with increasing amounts of IGF-1R inhibitors for $48 \mathrm{~h}$, and cell viability 
a

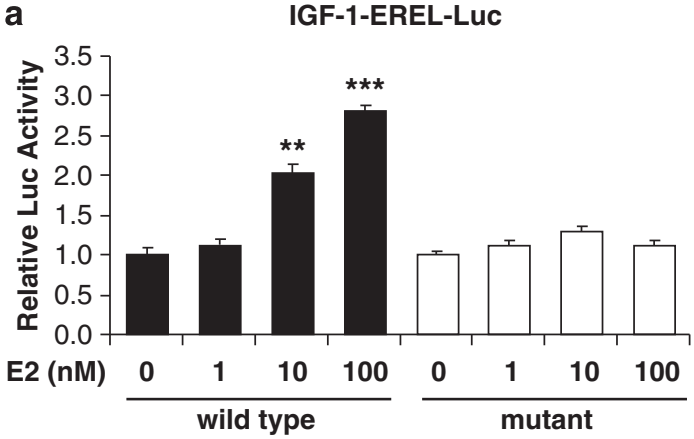

b Consensus ERE-Luc

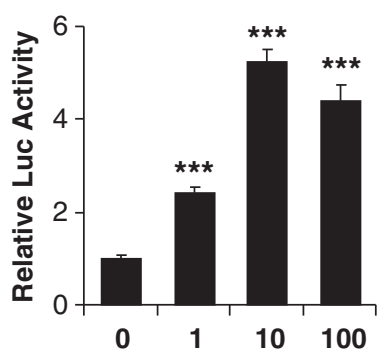

C

IGF-1-EREL-Luc
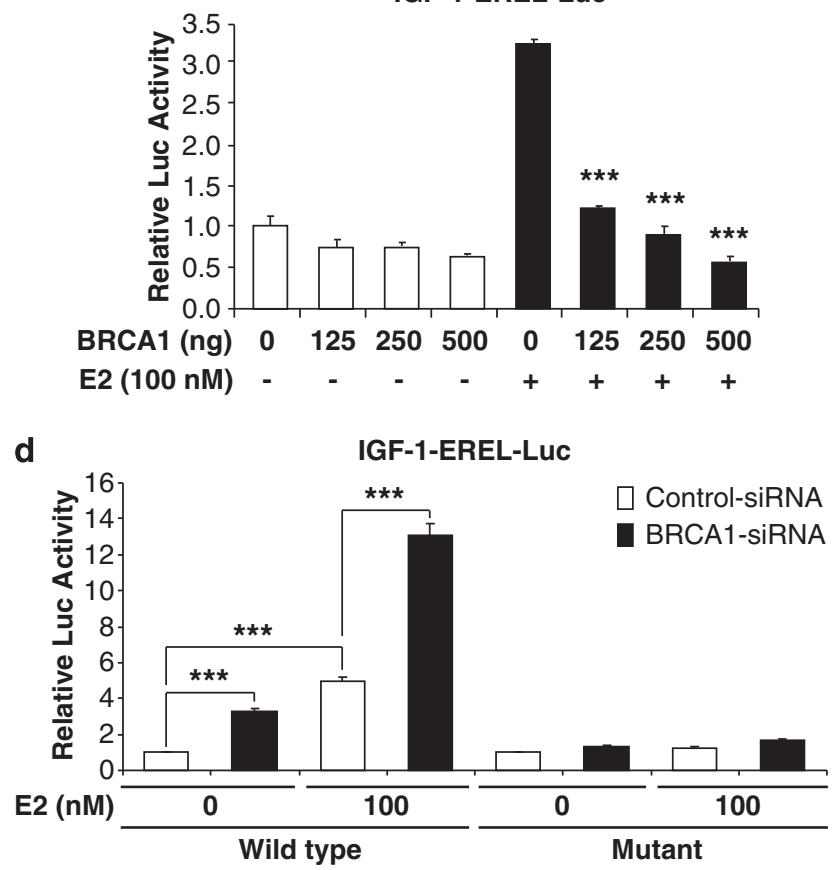

Figure 3 Regulation of IGF-1-EREL-Luc reporter activity by BRCA1 in the presence or absence of estradiol (E2). (a) MCF7 cells transfected with IGF-1-EREL-Luc (wild type versus mutant) or (b) consensus ERE-Luc for $24 \mathrm{~h}$ were further treated with or without $\mathrm{E} 2$ under estrogen-deprived conditions. After $24 \mathrm{~h}$ of treatment, cells were harvested and luciferase activity was measured as described in Materials and Methods. (c) Effects of wild-type BRCA1 overexpression on the wild-type IGF-1-EREL-Luc promoter reporter in the absence or presence of E2. Cells transfected with the wild-type IGF-1-EREL-Luc reporter and increasing amounts of BRCA1 expression vector (pcDNA3-BRCA1) overnight were further incubated in the absence or presence of $\mathrm{E} 2$ under estrogen-deprived conditions. Then, cells were harvested to measure luciferase activity. (d) Effects of BRCA1-KD on the wild-type IGF-1-EREL-Luc promoter reporter. Cells pretreated with siRNA (control versus BRCA1) for $72 \mathrm{~h}$ were transfected with wildtype IGF-1-EREL-Luc for $24 \mathrm{~h}$ under E2-stimulated conditions and luciferase activity was measured. (a-d) Representative data from two independent experiments performed in triplicate are shown as mean \pm S.E.M. ${ }^{* *} P<0.01$ and ${ }^{* * *} P<0.001$

was measured by MTT assay. As results, BRCA1-KD cells showed increased sensitivity to both inhibitors in a dose-dependent manner (Figure 7a). Two other IGF-1R inhibitors, OSI-906 and AG 1024 (Supplementary Table S1), also preferentially inhibited proliferation of BRCA1-KD MCF7 cells (Figure $7 \mathrm{~b}$ ). As expected, transient overexpression of wild-type BRCA1 conveyed resistance of MCF7 cells to BMS-536924, OSI-906, and AG 1024 (Figure 7c). Results were confirmed in another $\mathrm{ER} \alpha$-positive breast cancer cell line, ZR-75-1, in which BRCA1-KD conferred increased sensitivity to IGF-1R inhibitors (Figure 7d).

Pharmacological inhibition of the IGF-1R/PI3K/AKT pathway reduces EREL-mediated transcription in BRCA1-KD cells. Given that IGF-1 induces transcriptional activation mediated by $E R E,{ }^{21,22}$ we hypothesized that BRCA1-KD-induced IGF-1R/PI3K/AKT signaling can participate in the activation of IGF-1 transcription through the EREL site. Both the neutralizing IGF-1 antibody and an IGF-1R inhibitor (OSI-906) significantly suppressed wild-type IGF-1-EREL-Luc reporter activity in BRCA1-KD MCF7 cells in a dose-dependent manner (Figure 8a). Additionally, the inhibitor of AKT translocation (Perifosine) or PI3K kinase (BEZ235) also significantly suppressed IGF-1 reporter activity induced by BRCA1-KD in MCF7 cells (Figure 8a). As expected, treatment of ICl182790 significantly suppressed BRCA1-KD-induced IGF-1-EREL-Luc reporter activity. Several studies show that activated AKT can contribute to ER $\alpha$ phosphorylation, which may be important for its transcriptional regulation activity. ${ }^{2}$ Because IGF-1-induced activation 


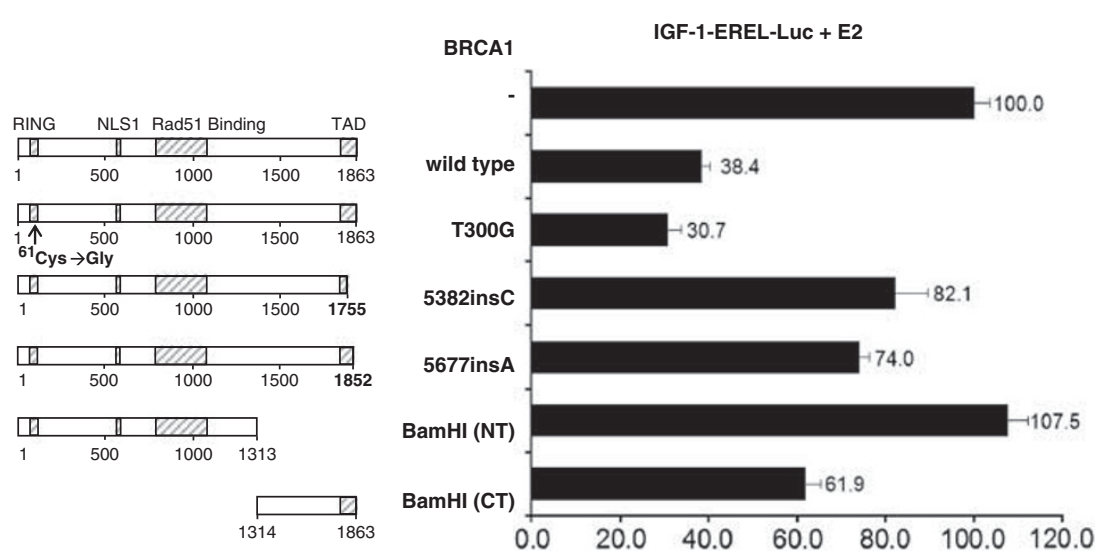

Figure 4 Effects of BRCA1 mutants on the wild-type IGF-1-EREL-Luc reporter in MCF7 cells. (Left) Schematic diagrams show the structure of the BRCA1 mutant constructs. (Right) Effects of wild and mutant types of BRCA1 expressing plasmid DNAs on IGF-1-EREL-Luc reporter. Cells transfected with the IGF-1-EREL-Luc reporter and various BRCA1 mutant expression vectors overnight were further incubated in the presence of E2 under estrogen-deprived conditions. Cells were then harvested to measure luciferase activity. Representative data from two independent experiments performed in triplicate are shown as mean \pm S.E.M.
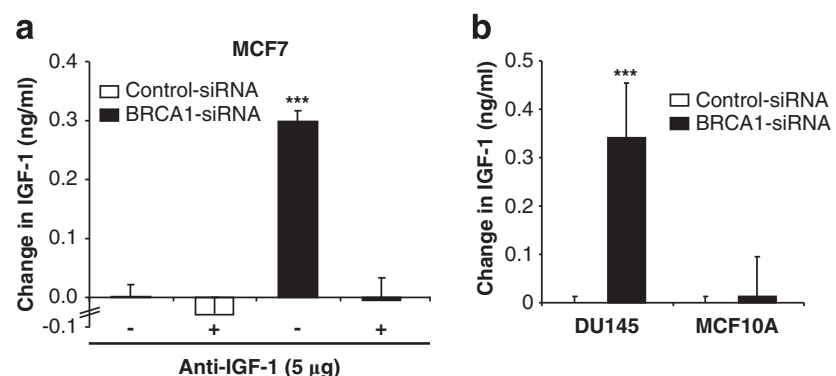

Figure 5 Effect of BRCA1-KD on secretion of IGF-1 protein. (a) The levels of secreted IGF-1 proteins in MCF7 cells transfected with siRNA (control versus BRCA1) in the absence or presence of neutralizing IGF-1 antibody were measured by ELISA assay as described in Materials and Methods. (b) The secreted IGF-1 proteins were measured by ELISA assay in DU145 or MCF10A cells transfected with siRNA (control versus BRCA1). ${ }^{* * *} P<0.001$

of IGF-1R/PI3K/AKT signaling in BRCA1-KD cells may continuously stimulate IGF-1 mRNA expression, we are proposing that BRCA1-KD will keep turning on this pathway in a 'positive feedback' manner (Figure 8b).

\section{Discussion}

There are several prior studies implicating BRCA1 in the regulation of the IGF-1R pathway: (a) BRCA1 negatively regulates IGF-1R transcription via the Sp1 transcription factor; ${ }^{23}$ (b) mRNA expression of several IGF-1R axis members (including Igf-1, Irs-1, Igf-1r, and Igfbp2) increases in the Brca1 ${ }^{\Delta 11 / \Delta 11} \mathrm{p} 53^{+/-}$mouse model; ${ }^{24}$ and (c) intratumoral IGF-1 protein is upregulated in clinical samples of breast cancer patients with BRCA1/2 mutations. ${ }^{9}$ In comparison, our study demonstrated that among IGF axis members (IGF-1, IGF-2, IRS-1, and IGF-1R), IGF-1 is the only transcript that is regulated by BRCA1 in the MCF7 human breast cancer cell line. In contrast to a previous finding in prostate cancer, ${ }^{25}$ IGF-1R mRNA levels are not significantly affected by BRCA1-KD in MCF7 cells. Currently, these discrepancies are not understood; differences in the induction of IGF axis members by BRCA1 loss may be due to unidentified genetic backgrounds of human versus mouse or breast versus prostate cells.

Several lines of evidence support the cross-talk between IGF-1R and ER $\alpha$ at different levels. ${ }^{2,26}$ For example, IGF-1 induces transcriptional activation of $E R \alpha$-target genes 21,22 and $E R \alpha$ can be activated by downstream factors of IGF-1R such as MAPK or AKT. ${ }^{2}$ In addition, ER $\alpha$ can activate IGF-1R signaling not only by transcriptional activation but also by nongenomic function. Membrane $\mathrm{ER} \alpha$ can rapidly induce activation of several kinases including PI3K, ERK, and AKT.2,26 Our data showed that transcriptional activation of the IGF-1 promoter, induced by BRCA1-KD, is downregulated not only by IGF-1R inhibitors (either a neutralizing IGF-1 antibody or an IGF-1R inhibitor) but also by inhibitors targeting PI3K or AKT. Although the non-genomic function of $E R \alpha$ in the absence of BRCA1 needs further investigation, our data suggest that IGF-1 might be produced at higher levels in breast cancers with a loss of BRCA1 function, which may induce a 'positive-feedback loop' in activating IGF-1R/PI3K/ $\mathrm{AKT} / \mathrm{ER} \alpha$ signaling.

In our studies, when endogenous BRCA1 was knocked down, proliferation seemed to rely more on the IGF-1R pathway in MCF7 and ZR-75-1 cells. In fact, the phosphoIGF-1R is detected in about $50 \%$ of breast cancer cells irrespective of their subtypes and is associated with poor survival rate. ${ }^{5}$ Our results suggest that the IGF-1R signaling pathway could be aberrantly overactivated in ER $\alpha$-positive breast cancer cells with defective BRCA1 (e.g. its low expression level, point mutation, and so on). Therefore, targeting the IGF-1R pathway in various ways could be a potential option for prevention or therapy of BRCA1-defective breast cancers. It is noteworthy that levels of BRCA1 are reduced in sporadic breast cancers without BRCA1 mutations. ${ }^{12,13}$ Although most of the established human breast cancer cell lines carrying BRCA1 mutations are ER $\alpha$-negative, three-dimensionally cultured primary mammary epithelial cells from BRCA1 mutation carriers have heterogeneous ER $\alpha$ status: $32 \%$ ER $\alpha$-negative, $44 \%$ mixed, $24 \%$ ER $\alpha$-positive versus $90 \%$ ER $\alpha$-positive in controls. ${ }^{27}$ Recently, ER-positive 


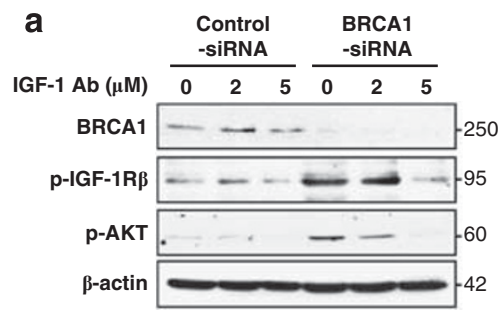

b

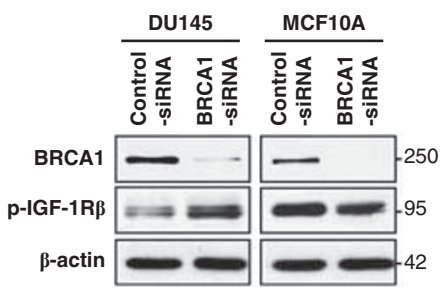

C

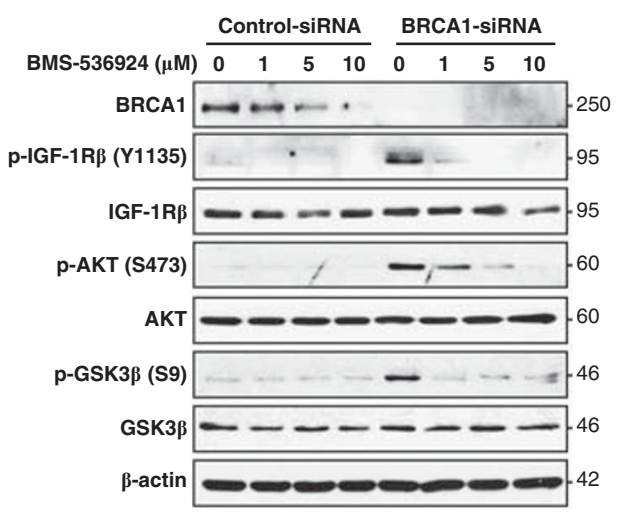

Figure 6 Autocrine activation of the IGF-1R pathway by IGF-1 in BRCA1-KD cells. (a) Cells pretreated with siRNA (control versus BRCA1) were incubated with an antiIGF-1-neutralizing antibody and their lysates were subjected to western blot analysis with indicated antibodies. (b) DU145 and MCF10A cells treated with siRNA (control versus BRCA1) were subjected to western blot analysis as in (a). (c) Cells pretreated with siRNA were incubated with BMS-536924 and changes of p-IGF-1R $\beta$, p-AKT, and $\mathrm{p}$-GSK3 were monitored by western blot analysis. $\beta$-actin was used as a loading control

tumors have been identified in BRCA1 mutation carriers that are $\geq 50$ years at the time of first diagnosis of breast cancer. ${ }^{28}$ It has been also reported that approximately $10-36 \%$ of breast cancers that occur in BRCA1 mutation carriers are ER-positive. ${ }^{28}$

We demonstrated that an insertional mutation (5382insC) and a carboxy-terminal deletion construct of BRCA1 are defective in their ability to suppress wild-type IGF-1-ERELLuc reporter activity. The 5382insC mutation occurs in approximately $0.4 \%$ of the Ashkenazi Jewish population ${ }^{29}$ and is the most frequently observed BRCA1 mutation in nonJewish populations. ${ }^{30}$ Like wild-type BRCA1, these BRCA1 mutants still physically interact with $\mathrm{ER} \alpha$ by their aminoterminal domains, ${ }^{20}$ but their mutation/deletion in the carboxyl-terminal domain may abolish their suppressive function on $\mathrm{ER} \alpha$-mediated transcriptional regulation.

We found that BRCA1 has little or no effect on E2-induced binding of $E R \alpha$ to IGF-1 promoter (Figures $2 b$ and $c$ ). This result implicates that the binding of ligand-bound $E R \alpha$ to IGF-1 promoter is independent of BRCA1 binding. Then, how does BRCA1 regulate IGF-1 transcription? Previously, it is postulated that the transcriptional repression of $\mathrm{ER} \alpha$ by $\mathrm{BRCA} 1$ occurs through estrogen-independent interaction between the amino-terminus of BRCA1 and the carboxy-terminal activation domain (AF-2) of $E R \alpha .{ }^{20}$ It was subsequently shown that p300 and cyclin D1 may compete with BRCA1 for ER $\alpha$-binding and reverse $B R C A 1$-mediated repression of $E R \alpha$ transcriptional activity. ${ }^{31,32}$ In our reporter assay, however, the carboxy-terminus-truncated BRCA1 completely lost the repression activity on the E2-induced IGF-1-EREL-Luc transcription. These results suggest that the carboxy-terminal repression domain of $\mathrm{BRCA} 1$ is further required to suppress E2-dependent $\mathrm{ER} \alpha$ transactivation of IGF-1 promoter. The function of carboxy-terminal repression domain of BRCA1 is not well understood yet, but BRCA1 interacts with several factors through this domain. In fact, BRCA1 interacts with a transcriptional repressor $\mathrm{CtIP}^{33}$ and the histone deacetylase complex including HDAC1 and HDAC2 $2^{34}$ through this domain. It has been also reported that association of BRCA1 with HDAC2 epigenetically represses oncogenic microRNA-155 via deacetylation of histone $\mathrm{H} 2 \mathrm{~A}$ and $\mathrm{H} 3$ on its promoter. ${ }^{35}$ In our data, BRCA1-KD itself induced IGF-1-EREL-Luc reporter activity in the absence of E2 (Figure 3d). Taken together, transcriptional corepressors may be recruited to $\mathrm{ER} \alpha$ by BRCA1.

Our data also indicate that transcription factors other than $\mathrm{ER} \alpha$ might regulate IGF-1 transcription in BRCA1-defective cancers. First, BRCA1-KD-induced IGF-1 mRNA expression is partially reduced by an estrogen antagonist ICI182780 in MCF7 cells under normal growth conditions, whereas expression of IGF-1 mRNA is completely reduced by ICl182780 in E2-stimulated BRCA1-KD MCF7 cells. This result suggests that other transcription factors, which are activated by serum-containing factors, may induce the expression of IGF-1 mRNA in BRCA1-KD MCF7 cells. Second, the carboxy-terminus of BRCA1 (BamHI (CT); aa 1314-1863), lacking the $E R \alpha$-interacting domain, still partially represses E2-induced transcription of the wild-type IGF-1EREL-Luc reporter in MCF7 cells. It is possible that BRCA1 interacts with other transcription factors through its carboxyterminal repression domain in the regulation of the IGF-1 promoter. Third, the effects of tumor-associated BRCA1 mutants are different between the EREL site of IGF-1 and consensus ERE. The BRCA1 T300G represses the IGF-1EREL-Luc reporter activity as strongly as wild-type BRCA1, but did not suppress the consensus ERE-Luc activity. ${ }^{20}$ These discrepancies also indicate that additional mechanisms including factors other than $\mathrm{ER} \alpha$ may exist in the regulation of the IGF-1 promoter. As reported, the EREL site has sequence homology to both consensus ERE and AP1 sequences. ${ }^{19}$ Interestingly, it has been reported that BRCA1 can interact with AP1 family proteins, Jun B and Jun D. ${ }^{36}$ Thus, transcription factors, such as the AP1 family proteins, may have important roles through these sequences. Further 
a

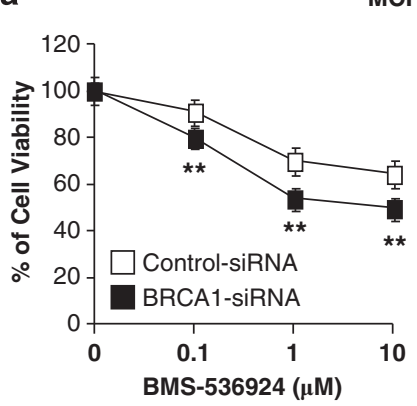

MCF7

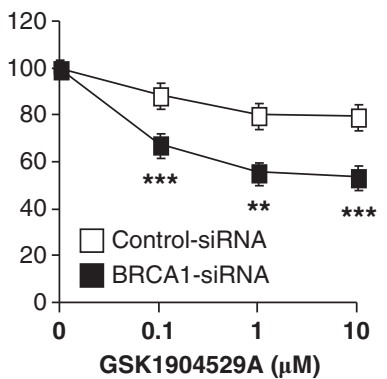

b

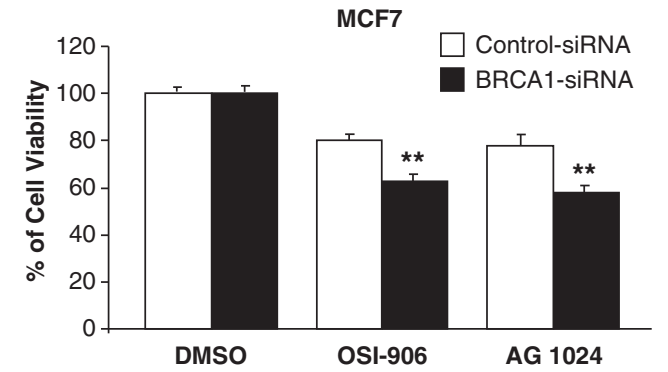

C

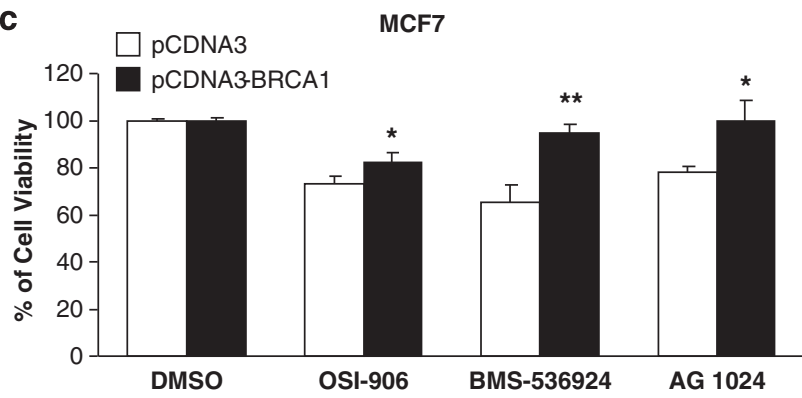

d

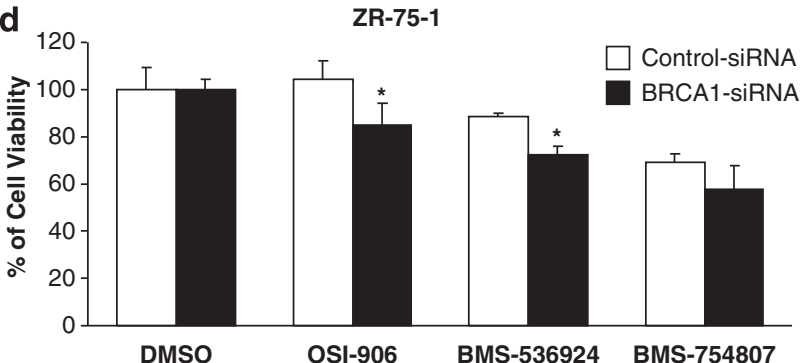

Figure 7 Sensitization of cells to IGF-1R inhibitors by BRCA1-KD. (a) MTT assays were performed to measure the viability of MCF7 cells pretreated with siRNA (control versus BRCA1) after an additional $48 \mathrm{~h}$ treatment of IGF-1R inhibitors (BMS-536924 or GSK1904529A). (b) Cells pretreated with siRNA as in a were treated with $1 \mu \mathrm{M}$ of IGF-1R inhibitors (OSI-906 or AG 1024) for $48 \mathrm{~h}$ and the viability of cells was measured by MTT assay. (c) Cells transfected with expression vectors (control versus BRCA1) were treated with $1 \mu \mathrm{M}$ of OSI-906, $10 \mu \mathrm{M}$ of AG 1024 , or $1 \mu \mathrm{M}$ of BMS-536924 for $72 \mathrm{~h}$ and the viability of cells was measured by MTT assay. (d) ZR-75-1 cells, pretreated with siRNA (control versus BRCA1), were further treated with IGF-1R inhibitors ( $1 \mu \mathrm{M}$ of OSI-906, $1 \mu \mathrm{M}$ of BMS-536924, or $1 \mu \mathrm{M}$ of BMS-754807, respectively) for $48 \mathrm{~h}$ and cell viability was measured by MTT assay. (a-d) Representative data are shown as mean \pm S.E.M. from at least three independent experiments performed in triplicate. ${ }^{\star} P<0.05$; ${ }^{\star \star} P<0.01$; and ${ }^{\star * *} P<0.001$

studies are required to fully understand the exact molecular mechanism by which BRCA1 regulates IGF-1 transcripts on its promoter elements.

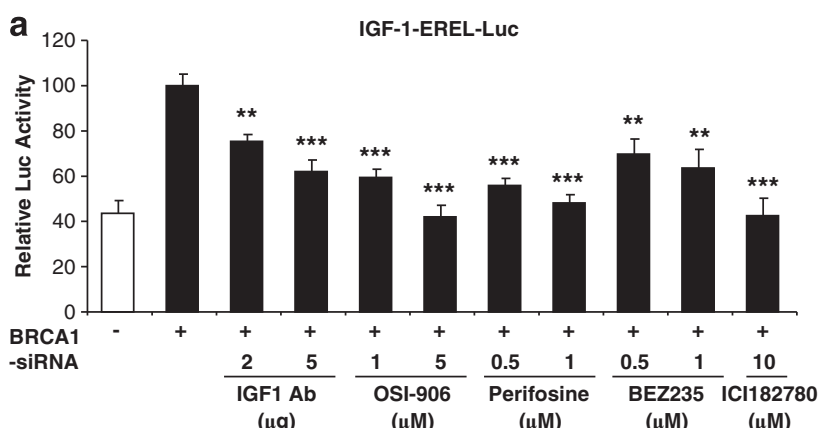

b

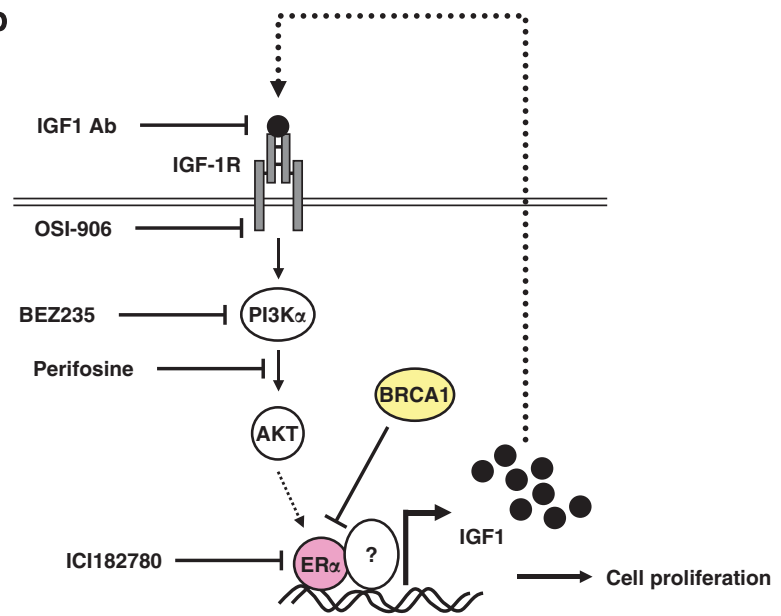

Figure 8 Pharmacological inhibition of IGF-1-EREL-Luc reporter activity in BRCA1-KD MCF7 cells. (a) MCF7 cells, pretreated with wild-type IGF-1-EREL-Luc and BRCA1 siRNA, were further treated with an IGF-1 monoclonal antibody or a small-molecule IGF-1R inhibitor (OSI-906), an AKT translocation inhibitor (Perifosine), a PI3K inhibitor (BEZ235), or an antiestrogen (ICl182780) for $24 \mathrm{~h}$ and subjected to the luciferase reporter assay. Representative data from two independent experiments are shown as mean \pm S.E.M. ${ }^{* \star} P<0.01$ and ${ }^{* * \star} P<0.001$. (b) Schematic diagram of the IGF-1/IGF-1R pathway regulation by BRCA1

Recently, it has been shown that tumor-suppressor function of BRCA1 depends on BRCA C-terminus domain in mouse model. ${ }^{37}$ In our data, carboxy-terminal domain of BRCA1 is required to repress E2-dependent activation of IGF-1 promoter. Our data also suggest that dysregulation of IGF-1 expression by loss of BRCA1 function may induce a positivefeedback loop, resulting further activation of IGF-1 transcripts through the IGF-1R/PI3K/AKT pathway. Taken together, the failure of several BRCA1 mutants in suppressing IGF-1 expression may be critical in the development, survival, and/or proliferation of certain types of ER-positive breast cancer.

\section{Materials and Methods}

Cell culture and reagents. All cell lines were purchased from American Type Culture Collection (Manassas, VA, USA). MCF7 and DU145 were maintained in Dulbecco's Modified Eagle Medium (DMEM) containing 5\% heatinactivated fetal bovine serum (HI-FBS; HyClone, Logan, UT, USA) and $100 \mathrm{U} / \mathrm{ml}$ penicillin/streptomycin. MCF10A was cultured in DMEM-F12 containing $5 \%$ horse serum (Invitrogen, Carlsbad, CA, USA), $10 \mu \mathrm{g} / \mathrm{ml}$ insulin, $10 \mathrm{ng} / \mathrm{ml}$ epidermal growth factor and $0.5 \mu \mathrm{g} / \mathrm{ml}$ hydrocortisone. ZR-75-1 cells were maintained in RPMI1640 containing $10 \% \mathrm{HI}-\mathrm{FBS}$ and $100 \mathrm{U} / \mathrm{ml}$ penicillin/streptomycin. Cell culture reagents were purchased from Invitrogen, Lonza (Basel, Switzerland), 
or Cellgro (Manassas, VA, USA). The cell viability was evaluated via the trypan-blue exclusion test using the Luna Cell Counter (Logos Biosystems, Gyunggi-Do, Korea). For estrogen-deprivation conditions, MCF7 cells were maintained in phenol-red-free DMEM (Invitrogen) containing 5\% charcoal-stripped FBS (HyClone). Inhibitor compounds were purchased from following sources: OSI-906 and BMS-754807 from MedKoo (Chapel Hill, NC, USA); AG 1024 from Enzo Life Science (Plymouth Meeting, PA, USA); BMS-536924 and GSK1904529A from Selleck Chemicals (Houston, TX, USA); and BEZ235 from LC Labs (Woburn, MA, USA). Stock solutions of compounds were made with dimethyl sulfoxide (DMSO) (except for BEZ235 in dimethylformamide and Perifosine in $\mathrm{H}_{2} \mathrm{O}$ ) and stored at $-20{ }^{\circ} \mathrm{C}$ in small aliquots. Estradiol (Sigma, St. Louis, MO, USA) and ICl182780 (Tocris Bioscience, Minneapolis, MN, USA) were dissolved in ethanol.

siRNA transfection. The cells were pretreated with $100 \mathrm{nM}$ siRNA for $72 \mathrm{~h}$, reseeded into either six-well plates for western blot and ELISA or 96-well plates for MTT assay, and then further transfected with $100 \mathrm{nM}$ of fresh siRNA using Lipofectamine 2000 (Invitrogen). For MTT assay, the day after transfection, media containing inhibitors were added to each well in triplicate. The siRNAs were obtained from Dharmacon (Lafayette, CO, USA): control-siRNA, 5'-GACGAGCG GCACGUGCACAUU-3'; BRCA1 siRNA, 5'-GAAGCCAGCUCAAGCAAUAUU-3'; and BRCA1 SiRNA, 5'-GAAGGAGCUUUCAUCAUUCUU-3'.

MTT assays. Cell proliferation was assayed at $48-72 \mathrm{~h}$ after treatment of compounds by adding $20 \mu \mathrm{l}$ of $5 \mathrm{mg} / \mathrm{ml}$ MTT solution per $100 \mu \mathrm{l}$ of growth medium. After incubation for $2-4 \mathrm{~h}$ at $37^{\circ} \mathrm{C}$, the media were removed and MTT solvent $(4 \mathrm{mM} \mathrm{HCl}, 0.1 \%$ Nonidet- 40 in isopropanol or absolute DMSO) was added to dissolve the formazan. The absorbance of each well was measured by ELX808 Microplate Reader (BioTek, Winooski, VT, USA). Viable cells were calculated as a percent of the control.

Construction of IGF-1 promoter and reporter gene assay. Human IGF-1 promoter reporter (IGF-1-1kb-Luc) containing $\sim 1 \mathrm{~kb}$ of the upstream region of human IGF-1 gene was purchased from SwitchGear Genomics (Menlo Park, CA, USA). PCR reactions were performed to amplify the EREL sequence on the IGF-1 promoter. The following sequences of primers were used: $p G L 3,5^{\prime}$-ACCA ACAGTACCGGAATGCC-3'; wild-type IGF-1 EREL, 5'-ACTCAATAACTTTGCCAG AAGAGGTTACGCGTGCTAGCCCGGGC-3'; mutant IGF-1 EREL, 5'-ACTC AATAACTTGAAGAGGTTACGCGTGCTAGCCCGGGC- $3^{\prime}$. PCR products were subcloned into the pCR2.1-TOPO vector (Invitrogen) and EREL-containing regions were digested using Sacl and Hindlll restriction enzymes and ligated into the pGL3-control vector. MCF7 cells in 24-well plates were transfected with $125 \mathrm{ng} /$ well of the reporter DNA, $50 \mathrm{ng} /$ well of the $\beta$-galactosidase expression vector, and increasing amounts of BRCA1 expression vector by Lipofectamine Plus (Invitrogen). Luciferase activities from cell lysates were measured by the Victor2 plate reader (PerkinElmer, Waltham, MA, USA) at the Genomics and Epigenomics Shared Resource at Georgetown University Medical Center and normalized to $\beta$-galactosidase activities.

DNA transfection. Expression vectors for wild-type or mutant BRCA1 protein are described previously. ${ }^{38,39}$ DNA transfection was performed using Lipofectamine Plus (Invitrogen) as described previously. ${ }^{39}$ After $24 \mathrm{~h}$ of transfection, cells were plated into either 24- or 48-well plates with normal growth medium. The day after plating, cells were treated with normal growth media containing inhibitors for 48-72 h. All experiments were performed in triplicate and MTT assay was used to measure the viability of cells.

qRT-PCR. qRT-PCR was performed in triplicate with the Fast SYBR green master mix (Applied Biosystems, Carlsbad, CA, USA) using an Applied Biosystems-Prism Sequence Detector System 7700 at the Genomics and Epigenomics Shared Resource, Georgetown University Medical Center, and analyzed with SDS software. The following primer sequences were used: BRCA1 (forward) 5'-CAGCGATACTTTCCCAGAGC-3', (reverse) 5'-GTCCCTTGGGGTTT TGAAAT-3'; IGF-1 (forward) $5^{\prime}$-GCTCTTCAGTTCGTGTGTGG-3', (reverse) $5^{\prime}$-CC TGCACTCCCTCTACTTGC-3'; IGF-2 (forward) 5'-ACACCCTCCAGTTCGTCTG T-3', (reverse) 5'-GGACTGCTTCCAGGTGTCAT-3'; IGF-1R (forward) 5'-CCAAA ACTGAAGCCGAGAAG-3', (reverse) 5'-ATCGATGCGGTACAATGTGA-3'; IRS-1 (forward) 5'-AAGCACCTGGTGGCTCTCTA-3', (reverse) 5'-AGAGTCTCCACCTG CATCC-3'; and GAPDH (forward) 5'-GTATGACAACGAATTTGGCTACAG-3', (reverse) 5'-AGCACAGGGTACTTTATTGATGGT-3'.
Chromatin immunoprecipitation (ChIP). ChIP assays were performed using the ChIP-IT assay kit (ActiveMotif, Carlsbad, CA, USA). The sheared chromatin was immunoprecipitated with an ER- $\alpha$ antibody (HC-20; Santa Cruz Biotechnology, Santa Cruz, CA, USA), BRCA1 antibody (Ab1 + Ab4; Calbiochem, Gibbstown, NJ, USA), or normal IgG. The following primers were used: IGF-1 promoter $\left(-111\right.$ to -312 ) (forward) $5^{\prime}$-TTGTCACCATGCCCAAAAAA-3, ${ }^{\prime}$, (reverse) $5^{\prime}$-TTGCGCAGGCTCTATCTGC-3' and IGF-1 non-ERE promoter region ( -956 to -797 ) (forward) $5^{\prime}$-CAGGTTTGAGTTATATGG-3', (reverse) $5^{\prime}$-TGCC GAGCTCTAAAACCC-3'.

Neutralizing IGF-1 antibody and IGF-1 ELISA. Human IGF-1 neutralizing antibody (AF-291-NA) was purchased from R\&D Systems (Minneapolis, MN, USA). For neutralizing IGF-1, siRNA-transfected cells were further treated with 2 or $5 \mu \mathrm{g}$ of IGF-1 neutralizing antibody for an additional $24 \mathrm{~h}$. Media $(50 \mu \mathrm{l})$ from siRNA-transfected cells were tested for IGF-1 concentrations using the human IGF-1 Quantikine ELISA kit (R\&D Systems) according to the manufacturer's protocol.

Western blots and antibodies. Western blot analyses were performed using cleared cell lysates as described previously. ${ }^{40}$ Antibodies used in this study were as follows: BRCA1 (C-20) (sc-642) from Santa Cruz Biotechnology; phospho-GSK3 $\beta$ (Ser9) (\# 9323), GSK3 $\beta$ (\# 9332), phospho-Akt (Ser473) (\# 9271), Akt (\# 9272), phospho-IGF-1R $\beta$ (Y1135) (\# 3918) and IGF-1R $\beta$ (\# 3027) from Cell Signaling (Danvers, MA, USA); and $\beta$-actin (A1978) and horseradish peroxidase-conjugated secondary antibodies from Sigma.

Statistical methods. The two-tailed Student's $t$-test was applied for statistical analysis. ${ }^{*}$ indicates $P<0.05$; ${ }^{* *}$ indicates $P<0.01$; and ${ }^{* * *}$ indicates $P<0.001$. For the bar graphs, ${ }^{*},{ }^{* *}$, and ${ }^{* * *}$ evaluated the statistical significance of comparisons with the controls of interest.

\section{Conflict of Interest}

The authors declare no conflict of interest.

Acknowledgements. This work was supported by Susan $\mathrm{G}$ Komen for the Cure (FAS0703858) and by R31-10069 (WCU Program) through the National Research Foundation of Korea funded by the Ministry of Education, Science and Technology. We appreciate the help of Dr Rashmi Nemade (BioMedText, Inc.) for helpful discussions and editing.

1. Ewing GP, Goff LW. The insulin-like growth factor signaling pathway as a target for treatment of colorectal carcinoma. Clin Colorectal Cancer 2010; 9: 219-223.

2. Fagan DH, Yee D. Crosstalk between IGF1R and estrogen receptor signaling in breast cancer. J Mammary Gland Biol Neoplasia 2008; 13: 423-429.

3. Pollak M. Insulin and insulin-like growth factor signalling in neoplasia. Nat Rev Cancer 2008; 8: 915-928.

4. Riedemann J, Macaulay VM. IGF1R signalling and its inhibition. Endocr Rel Cancer 2006; 13: S33-S43.

5. Law JH, Habibi G, Hu K, Masoudi H, Wang MY, Stratford AL et al. Phosphorylated insulinlike growth factor-l/insulin receptor is present in all breast cancer subtypes and is related to poor survival. Cancer Res 2008; 68: 10238-10246.

6. Hewitt SC, Li Y, Li L, Korach KS. Estrogen-mediated regulation of Igf1 transcription and uterine growth involves direct binding of estrogen receptor $\alpha$ to estrogen-responsive elements. J Biol Chem 2010; 285: 2676-2685.

7. Shang Y, Brown M. Molecular determinants for the tissue specificity of SERMs. Science 2002; 295: 2465-2468.

8. Sasaki $\mathrm{H}$, Hayakawa J, Terai $\mathrm{Y}$, Kanemura M, Tanabe-Kimura A, Kamegai $\mathrm{H}$ et al. Difference between genomic actions of estrogen versus raloxifene in human ovarian cancer cell lines. Oncogene 2008; 27: 2737-2745.

9. Hudelist G, Wagner T, Rosner M, Fink-Retter A, Gschwantler-Kaulich D, Czerwenka K et al. Intratumoral IGF-I protein expression is selectively upregulated in breast cancer patients with BRCA1/2/ mutations. Endocr Rel Cancer 2007; 14: 1053-1062.

10. Miki Y, Swensen J, Shattuck-Eidens D, Futreal PA, Harshman K, Tavtigian S et al. A strong candidate for the breast and ovarian cancer susceptibility gene BRCA1. Science 1994; 266: $66-71$

11. Thompson D, Easton D. Breast Cancer Linkage Consortium. Variation in BRCA1 cancer risks by mutation position. Cancer Epidemiol Biomarkers Prev 2002; 11: 329-336. 
12. Wilson CA, Ramos L, Villaseñor MR, Anders KH, Press MF, Clarke K et al. Localization of human BRCA1 and its loss in high-grade, non-inherited breast carcinomas. Nat Genet 1999; 21: 236-240.

13. Esteller M, Silva JM, Dominguez G, Bonilla F, Matias-Guiu X, Lerma E et al. Promoter hypermethylation and BRCA1 inactivation in sporadic breast and ovarian tumors. J Natl Cancer Inst 2000; 95: 564-569.

14. Rosen EM, Fan S, Pestell RG, Goldberg ID. The BRCA1 gene in breast cancer. $J$ Cell Physiol 2003; 196: 19-41.

15. Mullan PB, Quinn JE, Harkin DP. The role of BRCA1 in transcriptional regulation and cell cycle control. Oncogene 2006; 25: 5854-5863.

16. Fan S, Wang J, Yuan R, Ma Y, Meng Q, Erdos MR et al. BRCA1 inhibition of estrogen receptor signaling in transfected cells. Science 1999; 284: 1354-1356.

17. Zheng L, Annab LA, Afshari CA, Lee WH, Boyer TG. BRCA1 mediates ligand-independent transcriptional repression of the estrogen receptor. Proc Natl Acad Sci USA 2001; 98 9587-9592.

18. Romagnolo D, Annab LA, Thompson TE, Risinger JI, Terry LA, Barrett JC et al. Estrogen upregulation of BRCA1 expression with no effect on localization. Mol Carcinogen 1998; 22 102-109.

19. Umayahara $\mathrm{Y}$, Kawamori R, Watada H, Imano E, Iwama N, Morishima T et al. Estrogen regulation of the insulin-like growth factor I gene transcription involves an AP-1 enhancer. J Biol Chem 1994; 269: 16433-16442.

20. Fan $S, M a ~ Y X$, Wang $C$, Yuan $R Q$, Meng $Q$, Wang JA et al. Role of direct interaction in BRCA1 inhibition of estrogen receptor activity. Oncogene 2001; 20: 77-87.

21. Klotz DM, Hewitt SC, Ciana P, Raviscioni M, Lindzey JK, Foley J et al. Requirement of estrogen receptor- $\alpha$ in insulin-like growth factor-1 (IGF-1)-induced uterine responses and in vivo evidence for IGF-1/estrogen receptor cross-talk. J Biol Chem 2002; 277: 8531-8537.

22. Cascio S, Bartella V, Garofalo C, Russo A, Giordano A, Surmacz E. Insulin-like growth factor 1 differentially regulates estrogen receptor-dependent transcription at estrogen response element and AP-1 sites in breast cancer cells. J Biol Chem 2007; 282: 3498-3506.

23. Sarfstein R, Maor S, Reizner N, Abramovitch S, Werner H. Transcriptional regulation of the insulin-like growth factor-I receptor gene in breast cancer. Mol Cell Endocrinol 2006; 252 241-246.

24. Shukla V, Coumoul X, Cao L, Wang RH, Xiao C, Xu X et al. Absence of the full-length breast cancer-associated gene-1 leads to increased expression of insulin-like growth factor signaling axis members. Cancer Res 2006; 66: 7151-7157.

25. Schayek H, Haugk K, Sun S, True LD, Plymate SR, Werner H. Tumor suppressor BRCA1 is expressed in prostate cancer and control insulin-like growth factor I receptor (IGF-IR) gene transcription in an androgen receptor-dependent manner. Clin Cancer Res 2009; 15 1558-1565.

26. Levin ER. Membrane oestrogen receptor $\alpha$ signaling to cell functions. J Physiol 2009; 587: 5019-5023.

27. Burga LN, Tung NM, Troyan SL, Bostina M, Konstantinopoulos PA, Fountzilas $\mathrm{H}$ et al. Altered proliferation and differentiation properties of primary mammary epithelial cells from BRCA1 mutation carriers. Cancer Res 2009; 69: 1273-1278.
28. Tung N, Wang Y, Collins LC, Kaplan J, Li H, Gelman R et al. Estrogen receptor positive breast cancers in BRCA1 mutation carriers: clinical risk factors and pathologic features. Breast Cancer Res 2010; 12: R12.

29. Struewing JP, Hartge P, Wacholder S, Baker SM, Berlin M, McAdams M et al. The risk of cancer associated with specific mutations of BRCA1 and BRCA2 among Ashkenazi Jews. N Engl J Med 1997; 336: 1401-1408.

30. Laitman Y, Borsthein RT, Stoppa-Lyonnet D, Dagan E, Castera L, Goislard M et al. Germline mutations in BRCA1 and BRCA2 genes in ethnically diverse high risk families in Israel. Breast Cancer Res Treat 2011; 127: 489-495.

31. Fan $S$, Ma $Y X$, Wang $C$, Yuan $R Q$, Meng $Q$, Wang JA et al. $p 300$ modulates the BRCA1 inhibition of estrogen receptor activity. Cancer Res 2002; 62: 141-151.

32. Wang C, Fan S, Li Z, Fu M, Rao M, Ma Y et al. Cyclin D1 antagonizes BRCA1 repression of estrogen receptor alpha activity. Cancer Res 2005; 65: 6557-6567.

33. Yu X, Wu LC, Bowcock AM, Aronheim A, Baer R. The C-terminal (BRCT) domains of BRCA1 interact in vito with CtIP, a protein implicated in the CtBP pathway of transcriptional repression. J Biol Chem 1998; 273: 25388-25392.

34. Yarden RI, Brody LC. BRCA1 interacts with components of the histone deacetylase complex. Proc Natl Acad Sci USA 1999; 96: 4983-4988.

35. Chang S, Wang RH, Akagi K, Kim KA, Martin BK, Cavallone L et al. Tumor suppressor BRCA1 epigenetically controls oncogenic microRNA-155. Nat Med 2011; 17: $1275-1282$.

36. Hu YF, Li R. Jun B potentiates function of BRCA1 activation domain 1 (AD1) through a coiled-coil-mediated interaction. Genes Dev 2002; 16: 1509-1517.

37. Shakya R, Reid LJ, Reczek CR, Cole F, Egli D, Lin CS et al. BRCA1 tumor suppression depends on BRCT phosphoprotein binding, but not its E3 ligase activity. Science 2011; 334: 525-528.

38. Kang HJ, Kim HJ, Kim SK, Barouki R, Cho CH, Khanna KK et al. BRCA1 modulates xenobiotic stress-inducible gene expression by interacting with ARNT in human breast cancer cells. J Biol Chem 2006; 281: 14654-14662.

39. Kang HJ, Kim HJ, Rih JK, Mattson TL, Kim KW, Cho $\mathrm{CH}$ et al. BRCA1 plays a role in the hypoxic response by regulating HIF- $1 \alpha$ stability and by modulating vascular endothelial growth factor expression. $J$ Biol Chem 2006; 281: 13047-13056.

40. Jones LP, Sampson A, Kang HJ, Kim HJ, Yi YW, Kwon SY et al. Loss of BRCA1 leads to an increased sensitivity to Bisphenol A. Toxicol Lett 2010; 199: 261-268.

Cell Death and Disease is an open-access journal published by Nature Publishing Group. This work is licensed under the Creative Commons Attribution-NonCommercial-No Derivative Works 3.0 Unported License. To view a copy of this license, visit http://creativecommons.org/licenses/by-nc-nd/3.0/

\section{Supplementary Information accompanies the paper on Cell Death and Disease website (http://www.nature.com/cddis)}

